\title{
AIDS in Hemophiliac Population
}

National Cancer Institute

\section{Source}

National Cancer Institute. AIDS in Hemophiliac Population. NCI Thesaurus. Code C4987.

AIDS related research with a minimum of $20 \%$ (or $\$ 100,000)$ relevance to individuals with hemophilia, a sex-linked hereditary blood defect that occurs almost exclusively in males and is characterized by delayed clotting of the blood and consequent difficulty in controlling hemorrhage even after minor injuries. (FMB) 